\title{
Recent African Refugees to Australia: Analysis of Current Refugee Services, a Case Study from Western Australia
}

\author{
Peter Hancock \\ Social Justice Research Centre, School of Psychology and Social Science \\ Edith Cowan University \\ 270 Joondalup Drive, Joondalup Campus, Joondalup \\ Western Australia 6127 \\ Tel: 61-8-6304-5804Ｅ-mail: p.hancock@ecu.edu.au
}

\begin{abstract}
In the last decade the number of African refugees arriving in Australia has increased significantly, to the extent to which by 2008 they outnumbered all other refugee and humanitarian entrants to Australia (for example, in 2004-2005 75\% of all refugee and humanitarian entrants to Australia were from Africa). Existing service provision models have been found to be ill-equipped to cope with this sudden influx and have struggled to cope with the unique needs of African refugees (trauma, cultural needs, racism and longer settlement adjustment periods compared to other groups) in particular. This paper is based on a data-base and literature analysis of the numbers, issues and problems faced by refugees in Western Australia. Its major aim is to provide researchers and policy-makers with a resource base from which they can further their understandings of the plight of refugees in developing nations. As such much of the paper is based on analysis of a large amount of literature and data from government agencies, designed to provide an exhaustive overview of refugees, their experiences and gaps in service provision in Western Australia.
\end{abstract}

Keywords: African refugees, Racism, Australian settlement programs, Integrated services

\section{Introduction}

This article discusses the domination of refugee services by African families and the current services provided to them in Australia. The paper provides valuable insights regarding the experiences, issues, needs and concerns of a large group of newly-arrived refugee and humanitarian entrants. If then focuses on Western Australia (WA), to provide readers with a case study of 1) numbers of refugees arriving in this state in recent years; 2) the efficacy of existing refugee services to these refugees and 3) an example of a new innovative pilot project offered in WA to meet gaps in existing refugee services.

Problems with Australia's refugee settlement issues were raised by Waxman, 1999; Taylor, 2004; Pittaway, 2004; and Mitchell, Kaplan and Crowe, 2006; and these will be discussed in detail below. This paper also highlights a new innovative programs (ISC - Integrated Services Project eg) and research regarding how to better integrate refugees into Western nations. The article also highlights the unique problems faced by African refugees and provides discussion and ideas as to how to provide more streamlined and effective services this group.

\section{Issues Emerge}

In 2005, an Across-Government Working Party on Settlement Issues for African Humanitarian Entrants (the Working Party) was established by the then Minister for Citizenship and Multicultural Interests, the Hon Bob Kucera MLA (OMI, n.d.). Chaired by the Hon. Margaret Quirk MLA, the aims of the Working Party were to identify emerging settlement issues of significance for African entrants in WA, propose strategies to address these needs, and enhance communication and coordination of service delivery.

Due to the volume and nature of the needs of humanitarian entrants, the Working Party identified a range of gaps in service delivery. Improvements were recommended in the areas of initial settlement, mental and physical health, education and training, family support and community development. Table 1 identifies the numbers of refugees by local government area to WA, for example to highlight the growing number of refugees to Australia per se.

\section{Context}

The Centre for Multicultural Interests (2005) and Hannah (1999) define a refugee as: "someone who has been forced to leave their country of origin and is unable or unwilling to return due to fear of persecution for reasons including: race, religion, nationality, or political opinion” (Hancock, McMeekin \& Bahn, 2008, p.4). However, Earnest, Housen \& Gilleatt (2007) define humanitarian entrants as "individuals whose human rights have been grossly violated in their country of origin" (Hancock, McMeekin \& Bahn, 2008, p.4).

Waxman, 1999; Taylor, 2004; Pittaway, 2004; Colic-Peisker \& Tilbury, 2006 have identified a number of issues refugees and humanitarian entrants face during the resettlement process in Australia including: 
The loss or destruction of their homes and possessions, particularly if forced to flee suddenly;

1) The likelihood that refugees and humanitarian entrants have endured devastating conditions such as poverty, trauma, conflict, violence and human rights abuses, with limited or no access to health care and education (Australian Government, 2006; CMYI, 2005; DIAC, 2007a; Mitchell, Kaplan \& Crowe, 2006; Pittaway, 2004).

2) They may have been forced to spend years in transition countries or overcrowded, under-resourced refugee camps, subjected to poor living conditions (CMYI, 2005). In 2004-2005, for example, approximately half of all assisted refugees and humanitarian entrants arriving in Australia had spent six years or more in refugee camps, with almost a third indicating a period of ten years or more (DIMIA, 2006).

3) Newly arrived refugees are presented with the challenge of adjusting to a completely different culture, language and value system during resettlement, often while coping with the effects of past trauma (DIAC, 2007b; Mitchell, Kaplan \& Crowe, 2006; Waxman, 1999).

4) Many African refugees are accustomed to pastoral, communal environments, but are forced into the urban, individualistic environment of Australia (Mitchell, Kaplan \& Crowe, 2006; Waxman, 1999).

The main priorities of refugees in resettlement include basic needs, finding employment, education, and health care. However, African humanitarian refugees encounter obstacles in securing these basic needs such as:

1) The lack of existing networks to gain information and advice, along with poor financial conditions, undermine opportunities to secure suitable accommodation (Waxman, 1999; Migrant Information Centre, 2007).

2) Employment opportunities for adult refugees are hindered by both discrimination and educational issues (Hannah, 1999). Approximately $35 \%$ of culturally and linguistically diverse migrants are both overeducated and underpaid for their skill level (Federal Race Discrimination Commissioner, 1997, cited in Colic-Peisker \& Tilbury, 2006).

3) Accessing education for adult refugees is difficult due to a lack of English proficiency, misinformation by support agencies who are often unable to keep up to date with information regarding the wide range of courses and entry pathways into educational institutions in the area, and many refugees who are successful in gaining entry into post-compulsory education institutions find themselves in circumstances of extreme financial difficulty and are forced to find employment prior to completion (Hannah, 1999, Iredale, 1994).

4) Accessing adequate health care is difficult due to a number of constraining factors including: language and cultural barriers, financial constraints and problems with finding a healthcare provider who understands the complex health needs and concerns of refugees (Davidson et al., 2004; Tiong et al., 2006; DIAC, 2007b). Refugees are likely to have a number of pre-existing health conditions upon arrival. These may include: higher rates of dental problems, nutritional deficiencies and infectious diseases due to the unhygienic conditions, poor nutrition and lack of access to health care and immunisation in their home countries (Davidson, Skull, Calache, Murray, \& Chalmers, 2006; Tiong et al., 2006; DIAC, 2007b).

\section{Community Perceptions of African Refugees}

The identifiable presence of dark-skinned African people in a 'white' dominated nation such as Australia makes them a target for scrutiny by the media (RRAC, 2002) and even by politicians. Such difference causes refugees to need more prolonged settlement services (Casimiro, Hancock \& Northcote, 2007). Sweeping, unverified claims and stereotyping impacts on community perceptions and treatment of African people, creating fear and suspicion. This creates potentially harmful consequences for the ethnic identity and wellbeing of individuals from that group (Andrews \& Sibbel, 2003; RRAC, 2002). For example, in 2007, the Australian Immigration Minister, Kevin Andrews, claimed that young African refugees are involved in "race-based gangs" and nightclub fights, and are engaging in crime and drinking in parks at night ("'Evidence' sparks new refugee row", 2007; Lampathakis, 2007).

The number of people who enter Australia through the Humanitarian Program (Refugees and the Special Humanitarian Programs (SHPs)) is particularly relevant to the potential size of the ISCs target group. In 2006-2007, the Humanitarian Program set a total of 13,000 new places for humanitarian entrants into Australia. The number of places that were designated for refugees was 6000 , whilst 7000 places were assigned for SHP entrants. The same total was set for 2007-2008 and the proportions of places designated to refugees and SHP entrants was expected to remain stable (DIAC, 2007b). Over the past five years, Africa has been the largest source for humanitarian entrants, with numbers peaking during 2004-2005, when $75 \%$ of the overall intake originated from Africa. In 2003-04, the proportion of African people assisted under the IHSS was 63\%, while in 2005-06 the figure was 60\% (DIMIA, 2006). However, in August 2007, the then Minister for Immigration, Kevin Andrews announced that Australia was reducing their refugee intake quota from Africa to 30\%, a significant decrease from 75\% in 2004-2005 (Black, 2007).

In 2006-2007, the number of assisted refugees and humanitarian entrants arriving in Australia from African countries was slightly lower than the previous year, yet still the highest proportion of all refugees (DIAC, 2007b). The majority of the African humanitarian entrants in 2006-2007 were from Sudan, with a total of 2260 out of 6348 all African entrants (DIAC, 2007b). The relatively recent arrival of the Sudanese population to Australia is 
highlighted by statistics from the 2006 Census. According to the 2006 Census, there were 19,050 people living in Australia who were born in Sudan (ABS, 2007). Of these, 13,249 had arrived between 2000 and 2005 inclusive (ABS, 2007).

In 2005-2007, 3729 humanitarian entrants arrived in WA, again with the majority from African countries (see Figure 1 following) (DIAC, 2007b). Of the total arrivals, almost a third originated from Sudan (DIAC, 2007b). The most recent available data from 2006-2007, shows that $69 \%$ of humanitarian entrants into WA were from African countries of origin (DIAC, 2007b). This clearly highlights that the ISCs will need to continue their focus on this particular clientele.

\subsection{Existing in Australia}

There are four significant programs currently operating in Australia that provide support to humanitarian entrants. However, these programs rely on traditional models of service delivery and tend to suffer problems commonly associated with silo approaches. These are: 1) The Integrated Humanitarian Services Scheme (IHSS); 2) The Settlement Grants Program (SGP); The Adult Migrant Education Program (AMEP); and 4) The Intensive English Centres (IECs). Additionally, there are several recent government initiatives in Australia that focus on settlement issues for humanitarian entrants. These are largely in response to the identified need for a whole-of-government approach (Australian Government, 2006; DIAC, 2007b).

The services provided by the IHSS are delivered through a large number of non-government and some commercial organisations on a contract basis (Urbis Keys Young, 2003). However, while all humanitarian entrants are eligible for the IHSS services, the degree of assistance they receive is determined according to their individual needs and their humanitarian entrant status (Urbis Keys Young, 2003). For example, people who arrive under the Refugee category receive the highest level of support and are potentially eligible for all IHSS service types. In contrast, SHP entrants are only eligible for Household Formation Support (HFS) and Early Health Assessment and Intervention (EHAI) (DIAC, 2003). Refugees who enter Australia illegally and are issued with a TPV are eligible for EHAI, including trauma and torture counselling (DIAC, 2003). The IHSS services assist eligible humanitarian entrants in the first six months of arrival in Australia.

A combined evaluation of the IHSS and Commonwealth-funded services for survivors of torture and trauma was conducted in 2003 by Urbis, Keys and Young; providing valuable insight and lessons for the ISCs. The IHSS was assessed to determine if its stated objectives were being met and to identify necessary modifications that would improve the efficiency, effectiveness and equity of the program. The evaluation also assessed the extent to which client needs were met in accordance with stated contracts and provided practical recommendations for improvements (Urbis, Keys \& Young 2003). A number of positive outcomes of the IHSS were acknowledged in the evaluation report, including that:

- $\quad$ The services are equitable;

- $\quad$ The services are provided promptly from the moment of arrival;

- The basic needs of clients are being adequately met;

- $\quad$ The clients are reporting high levels of satisfaction with the services; and

- $\quad$ The service delivery is consistent with the IHSS principles (Urbis, Keys \& Young, 2003).

However, a number of areas requiring attention were also identified in the evaluation report, including that the IHSS generally exhibited:

- $\quad$ A lack of common understanding of what initial settlement needs constitute;

- $\quad$ Confusion regarding the appropriate degree of assistance;

- $\quad$ Confusion regarding when and how referrals should be made;

- $\quad$ A lack of coordination between services;

- Some degree of duplication of services;

- A lack of continuity of services after the initial six month period ended; and

- Ineffectiveness in meeting the immediate physical health needs of entrants (Urbis Keys Young, 2003).

The Settlement Grants Program (SGP) was introduced in 2005 in response to the findings of a review of settlement services (DIAC, 2007a). The aim of the SGP is to provide funding for organisations that endeavour to help newly arrived refugees settle in Australia, particularly after the six month IHSS eligibility period expires (DIAC, 2007a). The programs that are funded by the SGP generally involve the provision of information and referrals, or support for communities and individuals in building their capacity to become self-reliant and self-directed. The services that are currently funded include: 'Orientation to Australia', which equips people with the skills to access mainstream services; 'Developing Communities' which organises community development projects; and, 'Integration - Inclusion and Participation', which runs projects to encourage new arrivals to interact with the broader community (DIAC, 2007a). 
Newly arrived refugees to Australia who over the age of 18 years and have little or no English proficiency are referred to the Adult Migrant English Program (AMEP) (AMES, 2007). AMEP provides free basic tuition in the English language for new migrants and refugees, as well as offering information about Australian society, culture and customs (AMES, 2007). Migrants and refugees alike are offered a maximum of 510 hours of free tuition to help them learn to speak, write, read and understand English (AMES, 2007). However, an individual's ability to learn English is influenced by a number of factors, including their age and prior level of education (DIAC, 2003). Further, an individual's ability to regularly attend classes may be dependent on transport and childcare access. The program has also been criticised for placing restrictions on the eligible period for initial enrolment (DIAC, 2003).

The four programs currently operating in Australia, namely the IHSS, SGPs, AMEP and IECs provide support to humanitarian entrants. These programs operate in silos, relying on a traditional service delivery model. The IHSS services assist newly arrived humanitarian entrants for the first six months of their arrival in Australia. The SGP services take up the resettlement issues once the clients have exited from the IHSS service by providing programs through NGOs. Both the IHSS and SGP services are supported by the AMEP (for refugees over eighteen years of age) which offers 510 hours of free English tuition, and the IECs which provides specialised English schooling for children for up to two years. These services provide many humanitarian entrants with valuable support and education. However, the services are overloaded and for African refugees who have often had a rural background with little or no formal education the six month IHSS service is too short. There are recognisable gaps in these services, leaving humanitarian refugees with resettlement issues that they cannot overcome with additional support.

\section{The Need for the ISC Project}

The 2007-2008 Australian Federal Budget recognised the need for complex case support services, to provide intensive case management for humanitarian entrants with a history of extreme torture, trauma or crisis. This was in part in response to a perceived failure of the IHSS and SGP to fully meet the needs of these individuals (DIAC, 2007b).

The Australian Government (2006) has acknowledged that more effective cooperation is needed between Commonwealth, State/Territory and Local government agencies, community groups and other key stakeholders. At a state level, settlement planning in WA is coordinated by the WA Interagency Settlement Group (WA-ISG), a recently established collaborative initiative that aims to implement strategies to address identified needs and service gaps (DIAC, 2007b). Members of WA-ISG include the Department of Immigration and Citizenship (DIAC), the Department of Employment and Workplace Relations, the Department of Education, Science and Training (DEST), the Department of Health and Ageing, the Department of Transport and Regional Services, Centrelink, the WA Office of Multicultural Interests (OMI) and the Western Australian Local Government Association (WALGA). The WA Office of Multicultural Interests (OMI, n.d.) asserted that a pilot project (The Integrated Pilot Project) ISC be implemented and provide a valuable foundation on which to build future collaborative initiatives.

The Integrated Service Centres and base it in two metropolitan schools in Perth, WA. The objectives of the ISC Pilot Project were:

1) To address the need for access to the types of services provided by the IHSS beyond the current period of eligibility for that program, in particular, those services that are most critical in meeting the most immediate and urgent settlement needs of clients;

2) To provide an integrated and coordinated model of service delivery to clients;

3) To increase the accessibility and utilisation of existing services by humanitarian entrants;

4) To promote partnerships and links with other agencies and service providers involved in the settlement of humanitarian entrants;

5) To provide a welcoming environment for ISC clients of all ages.

The ISC Project was piloted in two locations, both of which also contained Intensive English Centres (IECs). In 2007, the IEC enrolments in these schools were:

6) School 1 (north metropolitan, 2007: 180 IEC students); and

7) School 2 (south metropolitan, 2007: 120 IEC students).

Over $70 \%$ of the enrolled students in the IECs were from Africa and although the ISC Project was developed for all refugee entrants to WA, in reality over $98 \%$ of its clients were African humanitarian entrants. All of the families serviced by the ISC's are students of the IECs.

The ISC schools service families from the three local government areas with the highest proportion of humanitarian refugees. Table 1 indicates that in 2006-2007 Wanneroo was ranked as the second most populated area vis-à-vis the settlement for humanitarian entrants in Perth, whilst Canning was ranked third. The City of Stirling (adjacent to the Koondoola ISC) had $42 \%$ of all humanitarian entrants to WA in the same year and was ranked as the most populated area of settlement for humanitarian entrants to WA (DIAC, 2007b). The suburbs 
housing African refugees in the City of Stirling are particularly supportive of humanitarian entrants in that the housing (usually public) is relatively more affordable in these areas; they are close to the main transport routes; there are NGO's that provide assistance within close proximity and there are religious venues and supporting ethnic businesses in the area. Some NGO's are operating in these suburbs in support of humanitarian entrants but these are predominantly in the City of Stirling. The suburbs surrounding the ISC2 have relatively fewer NGOs, government and other refugee services compared to the ISC1.

At a national level, the 2007-2008 Federal Budget allocated AUD\$35.2 million for the purpose of establishing complex case support services, to provide intensive case management for entrants with exceptional needs. This decision was made on the basis that current services, such as the Integrated Humanitarian Services Scheme (IHSS) and the Settlement Grants Program (SGP), were not effectively meeting the needs of those individuals who were subject to extreme torture, trauma or crisis events in their home country (DIAC, 2007b). The shortcomings of the two programs, the IHSS and the SGP, are highly relevant to the ISCs and highlight the need for additional services, and services that are far more streamlined and user friendly than the silo approach that currently dominates Australia's settlement programs.

\section{African Refugees Resettlement Needs}

As noted in the literature reviewed above African humanitarian entrants to Australia typically require more intensive settlement assistance than the current IHSS provides. The evaluative research found that the IHSS service is under considerable strain and is struggling to cope with new refugee arrival, and hence is in general only able to provide a limited service.

The literature has indicated that the IHSS and Special Grants Programs (SGP's) "were not effectively meeting the needs of those individuals who were subject to extreme torture, trauma or crisis events in their home country" (Hancock, McMeekin \& Bahn, 2008, p.14). This is further supported by an ISC staff member who stated that:

"Usually the clients are exited earlier than the IHSS program, so when they are exited they still have huge problems. Things like accommodation, some health issues that have not been tackled and in respect of 200's and 202 's (visas) they fall out of the system. So we pick them up in the ISC, we actually complete the work of IHSS".

Although these entrants have completed the six month IHSS settlement program, very little of the information passed on by this service is retained. The literature has revealed that DIAC (2007b) reported an "overwhelming 'saturation' of information upon arrival ... is a problem for humanitarian entrants in Western Australia" (Hancock, McMeekin \& Bahn, 2008, p.9). An ISC staff member stated that:

"Settlement is still a problem for them, they don't know the system because they are bombarded with so many things on arrival, so when they begin to settle down they begin to struggle and they can't remember".

The African humanitarian entrants have often spent many years in refugee camps awaiting migration to Australia and other countries, and many have little knowledge of the English language or awareness of life in a developed country like Australia. The literature indicates that Mitchell, Kaplan and Crowe (2006); Waxman (1999) and DIAC (2007b) reported that "newly arrived entrants are presented with the challenge of adjusting to a completely different culture, language and value system during resettlement" (Hancock, McMeekin \& Bahn, 2008, p.5).

\section{Examples of Holistic Responses}

The following are two examples of the ways in which the ISC Project has offered a holistic approach to the families utilising the Project. The narratives come from two project workers from the ISCs.

"One I can think of relates to a Buridian family, single mother with 3 boys. For a short period the main issues were nursing issues. As things went along other things developed to do with housing concerns and needing some assistance with food. Further down the road counselling issues presented, domestic violence, family functioning issues, mum's depression, child's concern, child's behaviour at school etc. and other issues such as socialisation for mum, Centrelink, mum needing to link to migration support services which is linked to grief and loss issues. So at that point we were able to sit down and say ok we've got a family with high needs, we've all got different roles here, we've all got different needs to follow up, we're able to discuss this and simplify things for mum and work out what are the priorities. At one point we linked in with DCP to deal with child protection issues and linked with the school psychologist".

"One example was a mother who was a sole care giver of 3 children under 8, socially isolated, the workers did a home visit, mum needed medical intervention, well there was no one to care for the children while she had surgery. So really the school nurses had to find and liaise with DCP about which agencies were going to take the responsibility of caring for 3 children after hours when mum was going in for surgery. She should have been under IHSS and there should have been a case worker supporting her, but there wasn't".

\section{Easing Pressure on Mainstream Services}

The African humanitarian entrants currently contributing to the refugee intake in Australia have placed considerable pressure on government and non-government agencies. Due to their traumatic background, African humanitarian entrants have higher needs than other entrants. The literature as reported by the Australian 
Government (2006); CMYI (2005); DIAC (2007); Mitchell, Kaplan and Crowe (2006); and Pittaway (2004); has indicated that "entrants and humanitarian entrants are likely to have endured devastating conditions such as poverty, trauma, conflict, violence and human rights abuses, with limited or no access to health care and education" (Hancock, McMeekin \& Bahn, 2008, p.5).

Many of the African entrants were previously living in rural Africa and have little or no knowledge of life in a city. The literature as reported by Mitchell, Kaplan and Crowe (2006); and Waxman (1999) indicates that "many African entrants are accustomed to pastoral, communal environments, but are forced into the urban, individualistic environment of Australia with little or no time to prepare for this drastic change" (Hancock, McMeekin \& Bahn, 2008, p.5). Settlement in Australia requires knowledge of how to access government services that provide aide and assistance. African humanitarian entrants are a group of entrants that generally have higher needs than other entrants that Australia has assisted in the past (Australian Government, 2006; CMYI, 2005; DIAC, 2007; Mitchell, Kaplan \& Crowe, 2006; Pittaway, 2004).

\section{Discussion}

It is difficult to come to terms with the notion that a group of refugees from a continent as large as Africa could be grouped together for the purposes of this research article. The use of the term 'African refugee' is a spurious one; however, I felt it was warranted in this case to highlight the unique needs of this group and the problems they face in re-settlement in nations like Australia. The fact that they have been singled out as African refugees in the Australian media and by politicians tends to compound the problem. However, for the sake of discussion, and not convenience, I have used this term to better enable policy makers, stakeholders and researchers to make informed choices in the future. It is clear that African refugees will continue to form the bulk of refugee intakes into developed nations for many years and based on this research, they bring with them different settlement needs and 'refugee experiences'.

\section{Conclusions}

This study has argued that newly arrived humanitarian entrants have complex settlement needs that were not well met by existing organisations and services in Australia and, in turn, in WA. From a human rights perspective, we have a specific duty to support humanitarian entrants, to understand their needs and to offer intensive support to aid their settlement and facilitate recovery from trauma, grief and loss. If moral arguments fail, for reasons of self-interest we should support this approach to integrated and intensive support for humanitarian refugees. Pragmatically, effective early intervention, prevents social exclusion and encourages more rapid integration. This offers benefits for the recipients because it allows them to settle more quickly and rebuild their lives. Effective settlement interventions also produce social benefits because recipients become productive members of the community more rapidly, and the Australian experience has shown that past generations of refugees ultimately made immense contributions to Australian society. Finally, effective and rapid settlement support programs reduce pressure on mainstream community medical, welfare and justice services in the long-term (this was evidenced by the example of the pilot project discussed in this paper).

Dr Peter Hancock, School of Psychology and Social Science, Edith Cowan University, is a Senior Lecturer specialising in Social Program Evaluation and Refugee Studies. He currently teaches Program Evaluation at Edith Cowan University.

\section{References}

Adult Migrant Education Services (AMES). (2007). English for migrants. Retrieved November 2, 2007, [Online] Available: http://www.ames.net.au/AMEP.

Andrews, A., \& Sibbel, A. M. (2003). Whose community is it anyway? The Mirrabooka Community Action Project. Perth.

Australian Bureau of Statistic (ABS). (2007). Census Ethnic Media Package. 2914.0.55.002 2006 Census Ethnic Media Package.

Australian Government. (2006). Measures to improve settlement outcomes for humanitarian entrants: Discussion paper. Canberra, ACT: Commonwealth of Australia.

Black, S. (2007, October 3). Kevin Andrews prods the Sudanese in the woodpile. Retrieved November 1, 2007. [Online] Available: http://www.crikey.com.au/Politics/20071003-Sudanese.html

Casimiro, S., Hancock, P. \& Northcote, J. (2007). Isolation and insecurity: Resettlement issues among Muslim refugee women in Perth, Western Australia. Australian Journal of Social Issues, 42 (1), 55-69.

Centre for Multicultural Youth Issues (CMYI) (2005). Refugee and CLD young people: Definitions. Information sheet no. 11. Carlton: CMYI.

Colic-Peisker, V., \& Tilbury, F. (2006). Employment niches for recent refugees: Segmented labour market in twenty-first century Australia. Journal of Refugee Studies, 19(2), 203-229. 
Davidson, N., Skull, S., Burgner, D., Kelly, P., Raman, S., Silove, D., Steel, Z., Vora, R., \& Smith, M. (2004). An issue of access: Delivering equitable health care for newly arrived refugee children in Australia. Journal of Paediatrics and Child Health, 40(9/10), 569-575.

Davidson, N., Skull, S., Calache, H., Murray, S., \& Chalmers, J. (2006). Holes a plenty: oral health status a major issue for newly arrived refugees in Australia. Australian Dental Journal, 51(4), 306-311.

Department of Immigration and Citizenship (DIAC). (2003). Report of the review of settlement services for migrants and humanitarian entrants. Department of Immigration and Citizenship.

Department of Immigration and Citizenship (DIAC). (2007a). Settlement Grants Program. Retrieved November 4, 2007, [Online] Available: http:/www.immi.gov.au/living-in-australia/delivering-assistance/settlement-grants/

Department of Immigration and Citizenship (DIAC). (2007b). Western Australia: Settlement trends and needs of new arrivals 2007. Canberra, ACT: Commonwealth of Australia. Retrieved September 9, 2007. [Online] Available: http://www.immi.gov.au/living-in-australia/delivering-assistance/government-programs/settlement-planning/_pdf/t rends_needs_wa.pdf

Department of Immigration and Multicultural Affairs (DIMIA). (2006). Report on performance. From DIMIA Annual Report 2005-2006. Retrieved September 9, 2007. [Online] Available: http://www.migration.gov.au/about/reports/annual/2005-06/DIMA_AR/default.html

Earnest, J., Housen, T., \& Gillieatt, S. (2007). A new cohort of refugee students in Perth: Challenges for students and educators. Retrieved November 3, 2007, [Online] Available: http://lsn.curtin.edu.au/tlf/tlf2007/refereed/earnest.html

Evidence sparks new refugee row. (2007, October 5). The West Australian, p.9.

Hancock, P., McMeekin, C., \& Bahn, S. (2008). The evaluation of the Integrated Service Centres Project: A literature review. Centre for Social Research Edith Cowan University: 1-39.

Hannah, J. (1999). Refugee students at college and university: Improving access and support. International Review of Education, 45(2), 153-166.

Iredale, R. (1994). Skills recognition and refugees: Migrants without options. Australian Journal of Social Issues, 29(3), 241-264.

Lampathakis, P. (2007, October 7). Sudan fury aimed at PM: Crime claims denied. The Sunday Times, p.26.

Migrant Information Centre (2007). "Finding a home": A research report on supporting newly arrived migrants and refugees to secure housing. Melbourne, Victoria: Migrant Information Centre.

Mitchell, J., Kaplan, I., \& Crowe, L. (2006). Two cultures: One life. Community Development Journal, 42(3), 282-298.

Office of Multicultural Interests (n.d.). Project brief: Integrated services centre pilot. Office of Multicultural Interests.

Pittaway, E. (2004). The ultimate betrayal: An examination of the experience of domestic and family violence in refugee communities. New South Wales: Centre for Refugee Research.

Refugee Resettlement Advisory Council (RRAC) (2002). Strategy for refugee young people. Canberra: Refugee Resettlement Advisory Council.

Taylor, J. (2004). Refugees and social inclusion: What the literature says. Migration Action, 26(2), 16-31.

Tiong, A. C. D., Patel, M. S., Gardiner, J., Ryan, R., Linton, K. S., Walker, K. A., Scopel, J., \& Biggs, B. (2006). Health issues in newly arrived African refugees attending general practice clinics in Melbourne. Medical Journal of Australia, 185(11/12), 602-606.

Urbis Keys Young. (2003). Evaluation of the Integrated Humanitarian Settlement Strategy (IHSS): Final Report. Belconnen, ACT: Department of Immigration and Citizenship.

Waxman, P. (1999). The residential location of recently arrived Bosnian, Afghan and Iraqi refugees and humanitarian entrants in Sydney, Australia. Urban Policy and Research, 17(4), 287-299.

Table 1. Settlement Locations of Humanitarian Entrants by Top 10 Local Government Areas (LGA), WA 2002-03 to 2006-07Source: DIAC (2007b, p.24)

\begin{tabular}{|c|c|c|c|c|c|c|}
\hline LGA & $\mathbf{2 0 0 2 - 0 3}$ & $\mathbf{2 0 0 3 - 0 4}$ & $\mathbf{2 0 0 4 - 0 5}$ & $\mathbf{2 0 0 5 - 0 6}$ & $\mathbf{2 0 0 6 - 0 7}$ & Total \\
\hline Stirling & 446 & 654 & 759 & 552 & 440 & 2851 \\
\hline Canning & 87 & 90 & 211 & 148 & 131 & 667 \\
\hline Wanneroo & 88 & 81 & 180 & 177 & 137 & 663 \\
\hline
\end{tabular}




\begin{tabular}{|c|c|c|c|c|c|c|}
\hline Bayswater & 45 & 92 & 49 & 70 & 80 & 336 \\
\hline Swan & 95 & 68 & 59 & 39 & 41 & 302 \\
\hline Cockburn & 79 & 43 & 77 & 16 & 32 & 247 \\
\hline Belmont & 19 & 22 & 42 & 59 & 65 & 207 \\
\hline Gosnells & 29 & 14 & 51 & 36 & 68 & 198 \\
\hline Victoria Park & 17 & 9 & 49 & 46 & 35 & 156 \\
\hline Perth & 1 & 2 & 6 & 30 & 92 & 131 \\
\hline Total (Top10) & $\mathbf{9 0 6}$ & $\mathbf{1 0 7 5}$ & $\mathbf{1 4 8 3}$ & $\mathbf{1 1 7 3}$ & $\mathbf{1 1 2 1}$ & $\mathbf{5 7 5 8}$ \\
Remainder & 107 & 97 & 225 & 228 & 319 & 976 \\
\hline Total & $\mathbf{1 0 1 3}$ & $\mathbf{1 1 7 2}$ & $\mathbf{1 7 0 8}$ & $\mathbf{1 4 0 1}$ & $\mathbf{1 4 4 0}$ & $\mathbf{6 7 3 4}$ \\
\hline
\end{tabular}

\section{Humanitarian Entrants to Western Australia 2005-2007}

Top 10 countries of origin

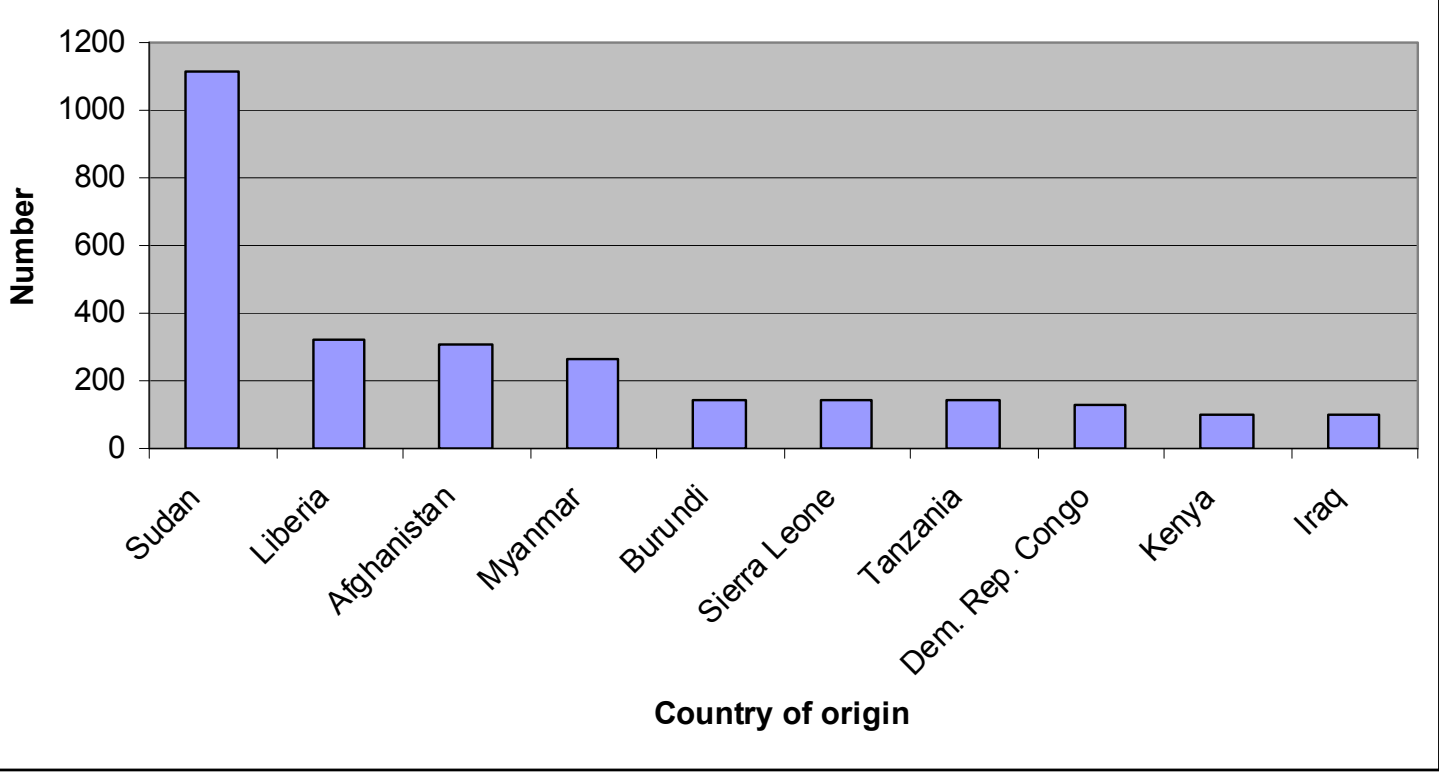

Figure 1. Humanitarian Entrants to Western Australia 2005-2007: Top 10 Countries of Origin Source: DIAC (2007b, p.23) 